\title{
NOTICE TO CONTRIBUTORS
}

Papers for consideration should be addressed to the editor (see inside front cover).

Papers must be as short as possible, twenty foolscap pages being considered a maximum. Those written as internal reports, i.e. with full descriptions and complete results of work, must be re-written concisely.

Manuscripts should be read critically, for example by a colleague, before submission, in order to avoid small errors, which might otherwise prolong the refereeing process.

\section{PRESENTATION}

Papers submitted should comply with the following points:

1. They must be typewritten with double spacing. The provision of two copies is advisable.

2. The title must be short.

3. A summary of not more than $250-300$ words is essential.

4. Routine mathematics should be omitted or given in an Appendix; the main text should contain only necessary equations.

5. SI Units must be used.

6. All symbols used in the text and figures, whether standard or not, must be listed in a Notation and the following points observed:

(a) Greek letters should be clearly written in ink and should also be indicated by name where they first appear.

(b) The use of dots, bars, and so on, over symbols, or the use of dots as multiplication signs and bars for brackets should be avoided.

(c) Suffixes and indices must be clearly indicated and complicated suffixes avoided.

7. References should be given in the form:

L C Squire. Experimental results for waveriders in certain off-design conditions. Aeronautical Quarterly, Vol.XXII, p 225, August 1971.

8. Illustrations should be reduced to a minimum. When the paper is first submitted they can be clear prints of graphs, sketches or photographs. If the paper is accepted, authors will be expected to provide black and white line drawings or graphs, in a form suggested by the editorial staff, and clear glossy photographs.

9. Tables should not duplicate information given in graphs.

\section{CONDITIONS OF PUBLICATION}

1. An author must obtain consent, where necessary, to use any material in his paper which is copyright or the property of any other person or his employers.

2. The copyright of every paper printed in The Aeronautical Quarterly is the property of The Royal Aeronautical Society. Permission to reprint or to use any paper will not be refused unreasonably.

\section{REPRINTS}

1. Authors will be entitled to 15 complimentary offprints of their papers, taken direct from the printed version.

2. Authors can order any number of additional reprints, re-imposed and with a title page. Order forms are sent to authors when proofs are submitted for correction.

The Aeronautical Quarterly is published at the Offices of The Royal Aeronautical Society, 4 Hamilton Place, London, W1V OBQ, at $£ 6.00$ net for a single number to non-members and $£ 1.50$ net for a single number to members of The Royal Aeronautical Society. None of the papers must be taken as expressing the opinion of the Council of the Royal Aeronautical Society unless such is definitely stated to be the case.

Telephone: 01-499 3515/9. Cables: Didaskalos, London, W1V OBQ 


\section{THE AERONAUTICAL QUARTERLY}

It is the aim of The Aeronautical Quarterly to attract not only original papers contributing to aeronautical science and engineering, and papers developing new or improved methods of analysis and experimental techniques, but also papers on allied sciences which have a bearing on aeronautical problems. The Aeronautical Quarterly is open to authors of any nationality and is not restricted to members of the Society.

The Editor makes efforts to reduce, as far as possible, the time lag between receipt and publication of a paper. Papers which do not require major revision after refereeing can usually be published within six months, especially if they are short ones.

\section{CONTRIBUTIONS}

The attention of authors is drawn to the "Notice to Contributors" inside this cover. In addition, a leaflet on the preparation of papers published by the Royal Aeronautical Society is available on request from the Editor.

\section{PRICE}

The Council of the Society has decided that in future The Aeronautical Quarterly must be self-supporting. This decision, together with increased printing costs and much increased postal charges, has made an increase in the subscription rate inevitable. The new prices are given below.

The Aeronautical Quarterly is published in February, May, August and November and the prices for Volume $\mathrm{XXXII,} \mathrm{which} \mathrm{include} \mathrm{postage} \mathrm{and} \mathrm{packing,} \mathrm{will} \mathrm{be} \mathrm{as} \mathrm{follows:}$

To Members of the Society

Per Part

Subscription (4 parts)
$£ 1.50$

$£ 6.00$
To Non-Members

$£ 6.00$

$£ 24.00$ 